\title{
Profissionais de saúde e 0 aborto: o dito e o não dito em uma capacitação profissional em saúde
}

Adriana Lemos ${ }^{(a)}$ Jane Araújo Russo(b)

Lemos A, Russo JA. Healthcare professionals and abortion: what is said and not said in a professional healthcare capacitation. Interface (Botucatu). 2014; 18(49):301-12.

The aim of this study was to analyze the perspective of professionals regarding abortion and its relationship with professional practice. These professionals participated of a course of The Women's Comprehensive Healthcare/

Contraception Program. It is a descriptive study with a qualitative and ethnographic approach involved participant observation, application of questionnaires and interviews with 11 healthcare professionals. The issue of abortion was addressed within the course in a problem-raising and dialogical manner, as a public health problem. In general, the predominant discourse during the theoretical module of the course was against the practice of abortion via arguments of a religious nature. Nevertheless, this stance became relative at the time of the interviews. Even if only partially, the course provided the group with a process of reflection on their professional practice, which is an important factor for those involved in the healthcare professionals' education.

Keywords: Induced abortion. Sexual and reproductive rights. Professional education. Healthcare professional.
O estudo objetivou analisar a visão de profissionais de saúde sobre aborto e sua relação com a prática profissional. Essas profissionais participaram de um curso do Programa de Atenção Integral à Saúde da Mulher/Contracepção. Trata-se de estudo descritivo, com abordagem qualitativa e etnográfica, utilizando observação participante, aplicação de questionários e entrevistas com 11 profissionais de saúde. O tema aborto foi abordado, no curso, de forma problematizadora e dialogal, como um problema de saúde pública. De forma geral, o discurso predominante durante o módulo teórico do curso foi pelo posicionamento contrário à prática do aborto via argumentos de natureza religiosa. Entretanto, este posicionamento se relativizou no momento das entrevistas. Ainda que parcialmente, o curso propiciou ao grupo um processo de reflexão sobre sua prática profissional, fator importante para os que estão envolvidos em capacitação de profissionais da saúde.

Palavras-chave: Aborto induzido. Direitos sexuais e reprodutivos. Capacitação profissional. Profissional de saúde.

\footnotetext{
(a) Departamento de Enfermagem de Saúde Pública, Escola de Enfermagem Alfredo Pinto, Universidade Federal do Estado do Rio de Janeiro. Rua Dr. Xavier Sigaud, $\mathrm{n}^{\circ} 290$. Rio de Janeiro, RJ Brasil. 22290-180. adrianalemos@unirio.br (b) Departamento de Ciências Humanas e Saúde, Instituto de Medicina Social, Universidade do Estado Universidade do Rio de Janeiro. Rio de Janeiro, RJ, Brasil. jane.russo@gmail.com
} 


\section{Introdução}

O movimento feminista e de mulheres, há pelo menos vinte anos, reivindica o enfrentamento da questão do aborto não só como um problema de saúde pública, mas como uma questão de cuidado da saúde e dos direitos humanos, sobretudo nos países onde a interrupção da gravidez é tipificada como crime - caso do Brasil. Este artigo é um recorte atualizado de uma pesquisa de doutorado, que teve como objetivo: descrever o enfoque dado ao tema do aborto durante um treinamento para profissionais da rede básica de saúde do Município do Rio de Janeiro, e analisar a visão das profissionais sobre o aborto e sua relação com a prática profissional.

Pesquisas com metodologias variadas reforçam a necessidade de se abordar o aborto como um problema de saúde pública ${ }^{1,2}$. Nas diretrizes normativas do Ministério da Saúde, o aborto é apresentado como um dos principais temas da agenda internacional no que diz respeito à saúde e aos direitos reprodutivos ${ }^{3}$. No Brasil, a interrupção da gestação só é permitida nos casos de risco de vida materna ou quando a gestação for resultado de violência sexual (estupro), devendo ser pautada na documentação necessária para garantir a legalidade da assistência - Artigo n 128 , I e II do Código Penal ${ }^{4}$. Em abril de 2012, o Supremo Tribunal Federal aprovou uma ampliação do permissivo legal que trata da interrupção da gravidez, incluindo, nos casos permitidos, a anencefalia fetal ${ }^{5}$.

Mulheres que buscam os serviços de saúde por complicações devido à realização de aborto de forma insegura são, muitas vezes, vítimas de preconceito dos profissionais que as atendem 6 . $O$ atendimento tende a ser punitivo e discriminador, gerando, nas mulheres, sentimentos de insegurança, angústia, culpa e humilhação, num flagrante desrespeito às diretrizes que preconizam o direito de todos a uma assistência humanizada e de qualidade. Não raro, os profissionais de saúde utilizam seus próprios critérios morais em suas práticas assistenciais, e adotam ações punitivas em seu atendimento às mulheres que praticam o aborto, agindo como verdadeiros juízes ${ }^{2}$. Um estudo realizado em Salvador (Bahia), com profissionais de um hospital que realiza o aborto previsto por Lei, apontou como representações mais recorrentes sobre aborto: a criminalização; o estigma por grupos religiosos; o treinamento e a falta de informações na formação. Demonstrou ainda a interferência das relações de gênero no atendimento nos casos de aborto provocado ${ }^{7,8}$.

Pesquisa realizada em cinco estados brasileiros das regiões Nordeste, Centro-oeste e Sudeste concluiu que a assistência a mulheres que buscam serviços de saúde no caso de aborto provocado é desumanizada, discriminatória e estigmatizada ${ }^{6}$. Dados de um dossiê sobre aborto inseguro no Estado do Rio de Janeiro destacam que a violência se traduz: no retardo do atendimento, na falta de interesse das equipes em escutar e orientar as mulheres, ou, mesmo, na discriminação explícita, com palavras e atitudes condenatórias e preconceituosas. É importante enfatizar que, em geral, são as mulheres pobres que abortam em condições de total insegurança, sofrendo com as graves consequências daí decorrentes, o que reforça as desigualdades sociais no atendimento em saúde ${ }^{9,10}$. Essas posturas devem ser compreendidas como parte integrante das relações de gênero tal como se expressam no atendimento dos serviços de saúde, associadas a valores morais e religiosos, resultando na estigmatização da mulher que aborta. Segundo Goffman ${ }^{11}$, o estigma diz respeito aos atributos considerados indesejados pela sociedade. Dentre os três tipos de estigma apresentados por Goffman ${ }^{11}$, podemos dizer que o abortamento se inclui naquele que trata dos desvios de caráter, na medida em que as mulheres que desejam interromper ou, de fato, interrompem uma gravidez, negam os ideais de feminilidade ${ }^{12}$, essenciais para a formação do caráter feminino.

É importante enfatizar que o cuidado à mulher que interrompe a gravidez diz respeito à garantia do direito à saúde, que é constitucional. O profissional de saúde, no exercício de sua prática profissional, seja na atenção hospitalar ou na atenção básica, é representante do Estado, e seus valores não deveriam sobrepor-se à Lei. Nessa perspectiva, quando uma mulher que provocou um aborto é mal atendida nos serviços públicos de saúde, seus direitos reprodutivos estão sendo violados. O aborto provocado fora dos limites da lei aponta para uma falha na atenção a esse direito, ou seja, para o caso de uma mulher (ou um casal) que teve pouco ou nenhum acesso à informação e aos meios possíveis de controle reprodutivo. 
O Programa de Atenção Integral à Saúde da Mulher (PAISM), implantado no Município do Rio de Janeiro na década de 1990, tinha justamente como objetivo incorporar os direitos reprodutivos ao programa de atenção à saúde da mulher. Sua implantação, nesse momento, deveu-se ao fato de profissionais de saúde ligadas ao movimento feminista estarem à frente da Gerência do Programa da Mulher da Secretaria Municipal de Saúde do Rio de Janeiro (GPM-SMS/RJ). Entre as medidas então tomadas, destacou-se a criação de um Centro de Treinamento em Atenção Integral à Saúde da Mulher - Espaço Mulher, que mantinha, entre suas atividades, a realização do curso PAISM/Contracepção, ministrado por uma equipe multiprofissional (enfermeiras, médica, educadora, psicóloga e assistente social), para profissionais de nível Superior (medicina, enfermagem e serviço social), com carga horária de 92 horas, com módulo teórico e prático. Utilizando uma metodologia participativa, o curso buscava enfocar as questões de gênero e a promoção dos direitos sexuais e reprodutivos.

\section{Percurso metodológico}

O estudo que apresentamos neste artigo foi conduzido no Espaço Mulher, local de realização do módulo teórico do curso de PAISM/Contracepção. Foi um estudo de cunho descritivo, utilizando uma abordagem qualitativa na perspectiva etnográfica ${ }^{13}$.

No primeiro dia do curso, realizado em meados dos anos 2000, foi aplicado um questionário para os 22 participantes inscritos, sendo que vinte o preencheram (13 enfermeiras, um enfermeiro, cinco assistentes sociais e uma médica). A observação participante ocorreu por dois meses, duas vezes na semana em período integral. Após o término do módulo teórico do curso, foram realizadas entrevistas gravadas por meio de equipamento digital. A seleção das informantes para as entrevistas foi um processo que aconteceu ao longo do trabalho de campo, e se pautou na análise das respostas aos questionários distribuídos no início e nas atitudes observadas ao longo do treinamento, tais como: ambivalência frente a temáticas consideradas centrais nesta pesquisa, além da disponibilidade pessoal para participação. Com o intuito de obter um grupo mais homogêneo, foram excluídos das entrevistas a única médica e o único homem. Foram entrevistadas sete enfermeiras e quatro assistentes sociais.

As entrevistas e o material da observação participante foram analisados por meio de análise temática ${ }^{14}$, na qual, por intermédio de uma matriz de análise, são identificados núcleos de sentido cuja frequência tem significado, na medida em que a presença de determinados temas se relacionam a valores de referência e modelos de comportamento das entrevistadas.

Esta pesquisa foi desenvolvida de acordo com a Resolução n 196/96 do Conselho Nacional de Saúde, aprovada pelo Comitê de Ética em Pesquisa da SMS/RJ. E, dessa forma, as informantes serão apresentadas com nomes fictícios.

\section{Resultados}

Apresento aqui um breve perfil das vinte participantes do curso, que preencheram o questionário pré-curso, "o espaço coletivo", perfil este que não se diferenciou significativamente do grupo das 11 informantes que participaram, também, das entrevistas, "o espaço privado". Das vinte informantes, 12 se autoidentificaram como brancas, cinco como negras, duas como pardas, e uma como parda/negra. Quanto à idade, nove tinham entre 28 e 34 anos, sete entre 41 e 46 anos, e quatro entre 53 e sessenta anos. A orientação religiosa católica foi referida por 12 das informantes, a evangélica por três, e o espiritismo/espiritualista por quatro, e uma não informou. Quanto à situação conjugal, 11 são casadas/ união consensual, cinco solteiras, três divorciadas/separadas, e uma não respondeu. Quanto a filhos, sete afirmaram não terem filhos. A zona norte foi a região citada por 12 das informantes como local de moradia, três citaram a zona oeste, três a zona sul, e duas a Baixada Fluminense. A renda familiar à época variou de cinco salários-mínimos para uma, entre 6,7 e 13 salários-mínimos para 12 das informantes, entre 18 e 29 salários-mínimos para cinco, e duas delas não informaram. Em relação ao 
tempo de formação, uma tem menos de cinco anos, nove têm entre cinco e dez anos, três mais de dez e menos de vinte, e sete têm de vinte a 29 anos de formadas; 17 informantes têm pós-graduação, dez em áreas afins à saúde pública.

A seguir, a descrição de dois momentos do trabalho de campo: o módulo teórico considerado como o "espaço coletivo", momento de observação participante das atividades do curso, e, posteriormente, as entrevistas, constituindo o que designamos como "espaço privado".

\section{O módulo teórico: espaço coletivo}

Quanto ao momento de observação participante do módulo teórico, diariamente, por volta das 8h30, algum membro da coordenação do curso iniciava a avaliação do dia anterior, e as treinandas expunham o que consideravam como interessante, importante ou cansativo. A técnica predominante de abordagem dos temas foi o uso de dinâmicas. Em geral, as dinâmicas visavam a discussão da temática por meio da interação entre os participantes, que expunham vivências e opiniões, através da realização de tarefas lúdicas, como recorte e colagem, trabalho corporal, ou, simplesmente, comentário sobre uma frase que remetia ao assunto colocado para debate.

Em dois momentos, no período inicial, duas coordenadoras afirmaram que o foco era "fazer pensar e mudar práticas", e que talvez o curso não incluísse o aprofundamento teórico sobre os temas a serem abordados. Estes foram: (1) PAISM; (2) promoção da saúde; (3) gênero; (4) raça e etnia; (5) doenças sexualmente transmissíveis (DSTs)/abordagem sindrômica das DSTs; (6) protagonismo juvenil; (7) aborto; (8) sexualidade; (9) mulher e aids; (10) violência contra a mulher; (11) métodos contraceptivos; (12) mortalidade materna; (13) serviço de contracepção, e (14) práticas educativas. Certamente, todos os temas estão articulados, mas, em função dos achados do campo e do foco deste artigo, a análise apresentada será sobre o tema aborto, que foi desenvolvido no quarto dia do curso.

Uma das coordenadoras distribuiu material para subsidiar a elaboração do seminário sobre os métodos contraceptivos, organizado pelas treinandas, e alguns textos sobre aborto foram disponibilizados por outra coordenadora. E ainda, as treinandas receberam vários textos de apoio sobre outros temas abordados no curso.

"Vamos falar sobre o aborto e as coisas relacionadas" foi a frase introdutória, e, rapidamente, foi pedido que se registrasse, por escrito, o que se pensava sobre a seguinte situação: "Minha menstruação atrasou, eu...". Algumas respostas foram transcritas no quadro, mas optou-se por trocar os papéis e redistribuí-los para leitura pelas treinandas. Seguem algumas das frases que surgiram: "Eu preciso investigar... A menstruação pode ser irregular". "Se transou sem precaução, toma POSTINOR". "Fiquei desesperada e fui para a farmácia". "Estou perdida, fiquei desesperada, pensei em abortar por duas vezes. O que eu faço?".

Diante da indagação da coordenadora sobre "o que fazer com esse desespero", uma treinanda narrou sua experiência, ao decidir realizar um aborto quando jovem. Todos ouviram silenciosamente e, logo em seguida, houve um burburinho, várias pessoas falando ao mesmo tempo, dirigindo-se ou não a ela. Uma treinanda afirmou ser a decisão pelo abortamento da mulher. Outra relatou ter engravidado em uma circunstância difícil da vida, mas não abortou e não se arrependeu. A primeira treinanda retornou à sua história, quando a coordenadora perguntou se mudou muita coisa dos anos 1970 para cá, época em que a treinanda realizou o aborto. Algumas disseram que sim e outras que não. A coordenadora prosseguiu, questionando sobre: a legislação brasileira, as mudanças na sociedade, e, ainda, a respeito de não se terem alcançado avanços no legislativo em torno da questão da descriminalização do aborto. O seu discurso tinha como pressuposto que avançar significava descriminalizar.

Em oposição a essa assertiva, uma treinanda declarou: “Porque as pessoas mudaram não necessariamente se liberaria o aborto". Enquanto outra assegurou que, sendo o Brasil o segundo maior país católico do mundo, o aborto jamais seria descriminalizado aqui. Mesmo com um discurso subentendido como favorável à descriminalização, a coordenadora não fomentou um debate sobre as diferentes posições das treinandas provocadas por seu comentário. 
Após o intervalo, foi realizada a dinâmica conhecida como "dança das cadeiras", que objetivava discutir os tabus, conceitos e preconceitos acerca do tema do dia. As treinandas andavam ao redor das cadeiras e, ao sinal da coordenadora para sentar, aquela que não havia conseguido assento lia uma frase que se referia a distintas questões em torno do abortamento.

"Abortei e fui denunciada pelo hospital".

Registro aqui um dos comentários de uma treinanda que nos dá a dimensão das contradições colocadas pelo tema: "Como profissional não sei se iria denunciar, mas como mulher fiz, sem saber a consequência". Para ela, como o aborto provocado é crime, o hospital "estaria certo" em denunciá-la. A coordenadora lembrou o sigilo profissional: "O profissional não poderia/deveria denunciá-la".

Percebem-se aí dois níveis de contradição: interna à própria treinanda (que tem posições diferentes "enquanto mulher" e "enquanto profissional"), e uma outra entre a coordenação e a maioria das treinandas. Esses dois níveis de contradição surgem de novo no episódio que relato a seguir.

Uma das treinandas leu a seguinte frase: "Porque é meu direito". Ao que outra retrucou: "Sou cristã, isso aí não é certo, é crime, um homicídio como qualquer outro, mas não vou julgar, tenho que sempre agir como profissional".

De novo percebemos, aí, uma contradição entre a posição oficiosa da coordenação e a posição contrária da treinanda, e, ao mesmo tempo, na fala da treinanda, a contradição entre sua opinião pessoal ("é crime") e sua posição enquanto profissional.

Neste momento, muitas treinandas reagiram à frase, todas contrárias à ideia de que o aborto é um direito. Uma afirmou que a pessoa que cometeu um aborto cometeu um erro, pois o direito à vida deve ser garantido. Outra defendeu os direitos do feto, e narrou a situação de uma amiga, que recebeu um diagnóstico de que a criança não sobreviveria, mas optou por manter a gestação, e a criança nasceu perfeita. Ela questionou: "Quantas crianças deixaram de nascer e poderiam ter sobrevivido?".

A coordenadora retomou a palavra, afirmando que, em certos momentos históricos, a religião cristã não se opunha ao aborto. Em seguida, apresentou o conceito de aborto e reafirmou a necessidade do respeito ao outro, independente do juízo de valor do profissional. Todas ouviram com atenção, em silêncio, mas à conclusão da explanação houve um alvoroço, todas falando ao mesmo tempo. Após o discurso da coordenadora sobre o atendimento discriminatório, em hospitais, de mulheres que praticam o aborto, uma das treinandas defendeu a qualidade da assistência, contrapondo-se à coordenadora. Esta encerrou a discussão afirmando:

"Reconhecemos que a mulher tem direito, em alguns países onde o aborto foi liberalizado, o número diminuiu. No nosso país é crime e há aumento da mortalidade materna em consequência do aborto". (Coordenadora responsável pela atividade do dia)

Apesar de as treinandas, em sua ampla maioria, afirmarem não reconhecer o direito ao aborto, a coordenadora concluiu a discussão sem levar em conta a opinião da maioria, pautando-se nas perspectivas da saúde pública e do movimento feminista.

\section{As entrevistas: o espaço privado}

Nos questionários e nas entrevistas realizadas com as 11 informantes, duas se mostraram, direta ou indiretamente, favoráveis ao aborto. No entanto, no momento das atividades em grupo, elas não colocaram suas opiniões, mesmo na presença da coordenadora, que apresentava postura favorável ao aborto.

Nas entrevistas, foi indagada a opinião sobre o aborto e se o curso havia proporcionado uma mudança de visão sobre o tema. O discurso predominante foi contrário ao aborto, sob justificativas religiosas. Uma informante declarou-se claramente favorável ao procedimento, enquanto três o consideravam um crime. Amanda foi enfática na sua oposição, com o argumento de defesa da vida e remetendo-se às variadas formas de evitar uma interrupção da gravidez. Curiosamente, ela declarou sentir-se fora de contexto, pelo fato de a maioria das colegas estarem vendo o aborto como natural, um 
direito da mulher, apesar de termos constatado que, ao contrário, a maioria das treinandas do módulo teórico desaprovava o aborto.

O acesso aos métodos como meio de evitar o aborto foi referido por Débora; para ela, é preciso separar o que se pensa do que ocorre no cotidiano do serviço. Contudo, o tom de sua narrativa é indicativo de sua dificuldade em efetuar esse tipo de separação, uma vez que sua visão da gravidez não prevista deixa de levar em conta todos os fatores de ordem emocional, familiar e econômica, entre outros, que operam numa gravidez, enfatizando uma avaliação moral da mulher que engravida "por descuido":
“A população tem meios para evitar [...] Não é por isso, pela baixa escolaridade, pela baixa renda que vai engravidar [...] eu acho que isso não é desculpa. O acesso está aí, toda unidade tem planejamento familiar, eu acho que toda, se não tem, uma próxima da área tem [...] Eu acho que é descuido mesmo". (Débora, grifo meu)

Dentre as informantes contrárias ao aborto, três ponderaram que, em função do risco de efetuar o procedimento em condições precárias, na ilegalidade, seria preciso rever a legislação, de modo a ampliar as situações passíveis de permissão legal. Beatriz, evangélica, contrária ao aborto, possui visões distintas, no que tange aos preceitos pessoais e profissionais, talvez por ter acompanhado um caso de aborto em sua família. Helena também explicitou um posicionamento análogo ao de Beatriz, pautado em sua vivência profissional com adolescentes:

\footnotetext{
“Pela minha religião e por mim mesmo, eu não concordo. Mas o fato de eu não concordar, não quer dizer que não tem casos que possam ser [...] Acho que é um direito da mulher essa escolha. Eu não deixaria, assim... a minha opinião intervir nada [...] eu acho que essa mulher teria o direito". (Beatriz, grifo meu)

“Falando de forma pessoal, eu sou contra o aborto, tenho essa concepção de ser contra. Mas, assim, diante da situação que a mulher faz o aborto de forma clandestina e isso prejudica sua saúde, o útero. Enfim, eu acho que é uma questão que deve ser revista [...] E eu atendo muitas meninas jovens [...] elas usam da forma mais precária possível, usa essa medicação, pensando que vai se livrar daquilo e, pelo contrário, adquire um problema maior". (Helena, grifo meu)
}

Isadora e Júlia apresentaram um discurso ambivalente, talvez por estarem em processo de reflexão e mudança de visão sobre a temática. Isadora demorou a conceder as respostas, talvez expressando conflitos entre sua convicção religiosa e sua posição como profissional, capaz de reconhecer o aborto como problema de saúde pública:

\begin{abstract}
"Acho que cada pessoa deve decidir em relação a si mesmo, quando tiver que fazer alguma dessas opções. Ao mesmo tempo, acho também controverso qualquer bandeira apoiando ou negando socialmente essas decisões [...]. Pra mim, o... quer dizer, eu, eu, eu sou, eu sou uma pessoa de formação católica [...] É, é eu tenho uma, assim, um sentimento muito grande... É... Religioso. De negação do aborto, ainda que eu entenda que como saúde, em termos de saúde pública a gente precisa ter um olhar diferente, um cuidado com as pessoas que não têm condição de pagar realmente pra fazer um aborto e acabam se submetendo as várias práticas, aí acabam muitas vezes morrendo, né? Mas, quer dizer, pra mim fica difícil". (Isadora, grifo meu)
\end{abstract}

Júlia, ainda que se opusesse ao aborto, expressou certos aspectos concernentes à complexa estrutura que cerca uma gravidez não planejada e, por consequência, a decisão pelo aborto. De certo modo, trata-se de um quadro semelhante ao apresentado por Isadora. 
“Fora da questão jurídica, acho o aborto muito arriscado para a mulher e agressivo [...] Eu nunca achei é, eu não discuto aborto, pelo menos aqui, como uma coisa jurídica, entendeu? [...] Eu acho que assim, cada caso é um caso. Entendeu? Às vezes, a pessoa tá num desespero, entendeu? Não teve aquela coisa de se prevenir, ou não teve porque não teve conhecimento ou tempo ou condições e precisou fazer, não queria um filho, não pôde ter aquele filho. Não sou nem a favor nem contra [...] vou tentar dar condições pra que aquela pessoa não faça. Até porque a gente não tem nada legalizado, isso pode tá prejudicando ela". (Júlia, grifo meu)

Lívia e Elza foram as únicas que revelaram o fato de terem realizado aborto, e estranharam o posicionamento da maioria das treinandas sobre o tema.

\begin{abstract}
"Sou a favor do aborto seguro, realizado por profissional médico [...]. É uma coisa que há muito tempo tinha que ser legalizada. A gente ouve falar de tantas moças que acabam morrendo por fazerem escondido, uma coisa tão simples, uma coisa médica que podia ser resolvida, e ainda ter alguém que é um chefe de uma unidade com influência sobre várias pessoas com uma coisa tão preconceituosa. Fiquei estarrecida, não podia acreditar que ainda existia isso". (Lívia)

“[...] quem opta por fazer, só aquela pessoa sabe por que está optando, então, você tem realmente que mostrar os prós e os contras e é aquela pessoa que vai decidir [...] eu vi, os profissionais não tão trabalhados para isso. Como é que essa pessoa consegue dar conta, trabalhar em cima disso com a população, com mulheres, sem conseguir desvencilhar esse preconceito? De repente, eu não tenho, por quê? Porque eu já passei [pelo aborto]". (Elza)
\end{abstract}

\title{
Discussão
}

A utilização de dinâmicas como principal abordagem pedagógica do curso é uma estratégia que atribui preeminência ao sentir, que valoriza a experiência, o vivenciado, e não a transmissão de conteúdos, característica da pedagogia tradicional. O uso de dinâmicas tem origem nos referenciais teóricos freireanos e no movimento feminista. Neste último caso, referimo-nos às práticas educativas que tiveram origem nas atividades dos 'grupos autônomos de mulheres', formados por feministas em serviços de saúde. Tais grupos implementaram propostas de vivências, objetivando a aprendizagem por meio da reflexão sobre a condição feminina, tida como objeto de um dispositivo de controle social.

O movimento feminista autônomo deu origem a uma vasta produção de material pedagógico e teórico, elaborado tanto em organizações não-governamentais e grupos autônomos como em instituições governamentais. ${ }^{15}$ (p. 56)

Era uma pedagogia calcada em metodologias que, surgidas no final dos anos 1970, baseavam-se em um processo de learning by doing (aprendendo através do fazer). Segundo Correa, a formulação das primeiras estratégias e instrumentos pedagógicos tinha como referência os conceitos de emancipação das mulheres/discriminação feminina ${ }^{16,17}$.

$\mathrm{Na}$ formulação de tais metodologias, o feminismo incorporou saberes e técnicas de outras áreas, como a psicologia (expressão e consciência corporal entre outros), a psicanálise, o método Paulo Freire, o materialismo histórico. Essa multiplicidade disciplinar não foi devidamente sistematizada e/ou conceituada, e tal conjunto se manteve submerso num suposto saber feminista original ${ }^{16}$, que parece ter sido incorporado pelas coordenadoras do curso observado, e muito valorizado nos relatos das treinandas.

A ênfase nas dinâmicas fez com que os textos oferecidos não fossem utilizados ou citados para subsidiar as polêmicas surgidas, embora seus conteúdos contribuíssem para reflexões sobre o tema. 
Tanto a observação do módulo teórico, quanto a informação obtida mediante questionários e entrevistas demonstraram uma quase total concordância do grupo no posicionamento contrário ao aborto, e no seu reconhecimento como crime. A narrativa das informantes se aproxima das reflexões de Barsted ${ }^{18}$, acerca da polêmica em torno do aborto nas Conferências do Cairo, em 1994, e de Beijing, em 1995. O foco se centrou no acesso à saúde, e não na perspectiva política do direito e da autonomia. Da mesma forma, quando as informantes julgam ser crime praticar o aborto, não se referem ao sentido penal, mas ao moral e religioso.

Os discursos expressaram uma postura contraditória. A narrativa de Isadora sobre o aborto ilustra essa antinomia:

\footnotetext{
"Pra mim, quer dizer, eu, eu, eu sou, eu sou uma pessoa de formação católica [...] É, é eu tenho uma, assim, um sentimento muito grande [silêncio] religioso de negação do aborto, ainda que eu entenda que como saúde, em termos de saúde pública a gente precisa ter um olhar diferente, um cuidado com as pessoas que não têm condição de pagar realmente pra fazer um aborto e acabam se submetendo às várias práticas, aí acabam muitas vezes morrendo, né? Mas, quer dizer, pra mim, fica difícil". (Isadora, grifo meu)
}

$\operatorname{Duarte}^{19}$ (p. 141), ao abordar a complexidade do fenômeno da religião nas sociedades modernas, afirma que o seu sentido se estrutura em três dimensões: "A da religião como identidade ou pertencimento; a da religiosidade como adesão, experiência ou crença e a do ethos religioso como uma disposição ética ou comportamental, associada a um universo religioso".

Não foi possível, neste trabalho, investigar as possíveis esferas estruturantes da acepção religiosa das informantes, mas alguns relatos permitem propor uma proximidade entre o posicionamento que emerge de seus discursos e a dimensão do ethos religioso.

Por meio do material etnográfico, identificamos, no grupo, uma opinião proeminentemente contrária ao aborto e favorável à sua categorização como crime. Uma diferença se apresenta quando a maioria exprime certo cuidado na abordagem do tema ao buscar demonstrar a necessidade e/ou intenção de separar opinião pessoal de atuação profissional.

Ao tratar do tema, as informantes evocavam, inicialmente, suas orientações religiosas como justificativa de seus pontos de vista, de modo a enfatizar a necessidade de respeitar e atender a mulher que aborta sem discriminação - separar "o pecado do pecador". Essa ética cristã de acolhimento e tolerância está intimamente vinculada ao ethos religioso tal como definido por Duarte ${ }^{19}$, uma vez que tais verbalizações se apresentaram independentemente das diferentes posições religiosas das informantes. Pode-se colocar como hipótese a ideia de ser possível a articulação entre esse ethos e o discurso dos direitos sexuais e reprodutivos. Em outros termos, embora apresentando uma retórica fundada nos valores cristãos (tolerância, compreensão e acolhimento), sem uma clara posição política pautada nas discussões dos organismos internacionais e acadêmicos, as informantes, de modo geral, apresentam um discurso próximo do respeito aos direitos reprodutivos.

Como vimos, os comentários de várias treinandas evidenciaram um posicionamento contrário à prática do aborto, e não contra a pessoa que o faz. A maioria abordou a necessidade do cuidado, do acolhimento e de uma postura de não-discriminação da mulher que aborta, demonstrando receio ao falar sobre o tema, e afirmando a necessidade e/ou a intenção de separar a opinião pessoal da atuação como profissional. Dessa forma, parece ser possível se opor moral e religiosamente ao aborto e, ao mesmo tempo, admiti-lo no âmbito profissional. Nos dois casos - a oposição em tese e o acolhimento na prática - a religião pode ser invocada como justificativa. Ouvir, dar apoio à mulher, não discriminá-la nem julgar as condições de realização do aborto acabou sendo a tônica das declarações.

Para a maioria das informantes, a opinião a respeito do aborto se transformou após o curso, não no sentido de tornar-se a favor ou contra, mas, sim, em passar a considerá-lo um problema de saúde pública, em perceber a necessidade de ampliar o debate e mudar a postura ao atender a mulher que aborta. Essa relativização frente ao tema apareceu na distinção entre a posição das informantes assumida coletivamente (no grupo-módulo teórico) e a posição assumida na entrevista. 
Podemos inferir que as treinandas, apesar do seu grau de escolaridade, provavelmente têm um acesso restrito à "modernização social e cultural; os debates internacionais sobre população, desenvolvimento, direitos humanos e das mulheres, etc." 20 (p. 96). A modernização social tem como um dos seus motores o processo de reflexividade. Através desse processo, os indivíduos, coletividades e instituições são submetidos a uma contínua reflexão sobre suas condições de ser e viver, provocando uma revisão das práticas e dos discursos acerca de tais condições, e de suas possíveis consequências. Pode-se dizer que o curso oferecido pelo Espaço Mulher fomentou esse processo de reflexividade, sendo, portanto, essencialmente modernizador.

No período de realização desse estudo, ainda não havia sido veiculada, pela mídia, a questão apresentada pelo ministro da Saúde sobre o aborto como problema de saúde pública (em 2007), e nem publicado o levantamento sobre as pesquisas realizadas, nos últimos vinte anos, no Brasil confirmando a tese do aborto como uma questão de saúde pública ${ }^{21}$. Do mesmo modo, o estudo sobre a magnitude do aborto no Brasil que estimou que 1.054.242 abortos foram induzidos em $2005^{2}$.

Recente publicação analisa as fronteiras entre argumentos morais, religiosos, políticos, e aqueles que dizem respeito aos direitos individuais, e expõe as desigualdades a que as mulheres se expõem em função da negação do direito ao aborto ${ }^{22}$. Ainda sobre a realização de pesquisas sobre aborto, outra apresenta as características não só de mulheres, mas, também, de homens jovens parceiros de mulheres que fizeram aborto ilegal, bem como seus itinerários e os métodos utilizados ${ }^{23}$, evidenciando iniquidades e desigualdades de gênero e econômica.

As informantes que vivenciaram a experiência de aborto, seja pessoal, como Lívia e Elza, familiar, como Beatriz, e profissional, como Helena, foram as que se mostraram mais abertas à possibilidade de reconhecerem um possível direito ao abortamento. Contudo, quando indagadas sobre direitos sexuais e reprodutivos, não associaram o aborto ao conjunto de direitos e, até mesmo, a uma opção individual.

\section{Considerações finais}

O tema aborto no curso de PAISM/Contracepção foi abordado de forma problematizadora e dialogal, e com enfoque sobre o aborto como um problema de saúde pública. As coordenadoras do curso estimularam a reflexão, a partir de discussões de casos do cotidiano dos serviços, e verbalizaram a intenção de propiciarem a reflexão e a mudança das práticas profissionais na atenção à mulher, na esfera da sexualidade e da reprodução. Tanto pela formação pautada nos saberes biomédicos quanto pelo suporte das ciências sociais e humanas, as enfermeiras e assistentes sociais, respectivamente, poderiam ter apresentado um discurso diferenciado em relação ao tema tratado neste artigo. No entanto, não houve distinção substancial, seja por categoria profissional, por idade, seja por orientação religiosa.

De forma geral, o discurso predominante foi contrário à prática do aborto, via argumentos de natureza religiosa e/ou moral, sobretudo no momento das atividades em grupo. A ambivalência, a relativização, ou, até mesmo, a flexibilidade frente ao tema fizeram-se presentes nos discursos de algumas informantes ao se referirem ao risco a que as mulheres se expõem pela proibição deste procedimento, especialmente no momento das entrevistas individuais. Deduzem ser preciso rever a legislação, para ampliar os casos permitidos por lei, além de reconhecerem tratar-se de um problema de saúde pública. Vale ressaltar que essa relativização em torno do aborto foi expressa, sobretudo, em entrevistas no espaço privado, enquanto no módulo teórico o posicionamento foi mais uniforme.

De acordo com os relatos das informantes, a mudança de visão sobre alguns temas, a aquisição de novos conhecimentos e a possibilidade de transformação de suas práticas foram as principais contribuições do curso desenvolvido pelo Espaço Mulher (centro de treinamento). De certa maneira, o curso propiciou ao grupo - ainda que parcialmente - um processo de reflexão sobre sua prática.

Vale ressaltar que o Espaço Mulher foi extinto em 2008. Com a expansão da Estratégia Saúde da Família, pela Secretaria de Saúde, por meio das Organizações Sociais de Saúde (OSS), em 2009, as atividades de qualificação dos profissionais relacionadas à Atenção à saúde da mulher foram descentralizadas para as Coordenações de Área Programática e para as próprias OSS. Pode-se inferir que, com a desarticulação 
deste importante espaço de qualificação, a reflexão sobre as práticas de atenção à saúde da mulher deixou de ser prioritária. Isto pode ser melhor esclarecido em pesquisas posteriores.

A pesquisa aqui apresentada demonstra que a mera discussão ou a transmissão de conhecimentos não é garantia de um processo de reflexão e de transformação das opiniões e práticas. Essa questão está posta aos gestores da atenção à saúde da mulher e aos órgãos de formação em saúde, sobretudo devido ao surgimento de discursos oficiais conservadores e pautados em fundamentalismos religiosos, como o Estatuto do Nascituro (PL 4782007), na Câmara dos Deputados, e sua "versão" Estadual, o Programa Estadual de Prevenção ao Aborto e Abandono de Incapaz (PL 4162011), que se opõem frontalmente aos direitos sexuais e reprodutivos, em particular no que diz respeito às mulheres. A afirmação de tais direitos é, sem dúvida, o grande desafio a ser enfrentado pelos responsáveis pelas atividades de educação permanente dos profissionais de saúde voltadas para a atenção à saúde da mulher.

\section{Colaboradores}

As autoras trabalharam juntas em todas as etapas de produção do manuscrito.

\section{Referências}

1. Diniz $D$, Medeiros M. Aborto no Brasil: uma pesquisa domiciliar com técnica da urna. Cienc Saude Colet. 2010; 15 Supl. 1:S959-96.

2. Monteiro MFG, Adesse L. Magnitude do aborto no Brasil: uma análise dos resultados de pesquisa [acesso $2010 \mathrm{Fev} 25$ ]. Disponível em: http://www.ccr.org.br/ uploads/eventos/mag_aborto.pdf

3. Ministério da Saúde. Secretaria de Políticas de Saúde. Área Técnica de Saúde da Mulher. Parto, aborto e puerpério: assistência humanizada à mulher. Brasília (DF): Ministério da Saúde; 2001.

4. Presidência da República. Decreto-Lei n 2.848 de 07 de dezembro de 1940. Diário Oficial da União, 31 Dez 1940.

5. Pimentel C, Jinkings D. Anencefalia: STF aprova interrupção da gravidez [Internet]. 2012 [acesso 2012 Abr 16]. Disponível em: http://www.agenciabrasil.ebc.com.br/ noticia/2012-04-12/anencefalia-stf-aprova-interrupcao-da-gravidez.htm

6. Soares GS, Galli MB, Viana APAL. Advocacy para o acesso ao aborto legal e seguro: semelhanças no impacto da ilegalidade na saúde das mulheres e nos serviços de saúde em Pernambuco, Bahia, Paraíba, Mato Grosso do Sul e Rio de Janeiro. Recife: Grupo Curumim; 2010.

7. Carneiro MF, Iriart JAB, Menezes GMS. "Largada sozinha, mas tudo bem": paradoxos da experiência de mulheres na hospitalização por abortamento provocado em Salvador, Bahia, Brasil. Interface (Botucatu). 2013; 17(45):405-18.

8. Zordo S. Representações e experiências sobre aborto legal e ilegal dos ginecologistas-obstetras trabalhando em dois hospitais maternidade de Salvador da Bahia. Cienc Saude Colet. 2012; 17(7):1745-54. 
9. Galli B, Viana P, Shiraiwa T. Dossiê sobre aborto inseguro para advocacy: o impacto da ilegalidade do abortamento na saúde das mulheres e na qualidade da atenção à saúde reprodutiva no Estado do Rio de Janeiro. Recife: Grupo Curumim; 2010.

10. Gesteira SMA, Diniz NMF, Oliveira EM. Assistência à mulher em processo de abortamento provocado: discurso de profissionais de enfermagem. Acta Paul. Enferm. 2008; 21(3):449-53.

11. Goffman E. Estigma: notas sobre a manipulação da identidade deteriorada. 4a ed. Rio de Janeiro: Editora LTC; 1988.

12. Norris $A$, Bessett $D$, Steinberg JR, Kavanaugh ML, Zordo S, Becker D. Abortion stigma: a reconceptualization of constituents, causes, and consequences. Womens Health Issues. 2011; 21 Supl. 3:S49-54.

13. Becker H. Método de pesquisa em ciências sociais. São Paulo: Hucitec; 1993.

14. Bardin L. Análise de conteúdo. Lisboa: Edições 70; 2006.

15. Carneiro F, Agostini M. Oficinas de reflexão: espaços de liberdade e saúde. Rio de Janeiro: Escola Nacional de Saúde Pública, Fundação Oswaldo Cruz; 1994.

16. Corrêa $S$, Camurça $S$, Xavier D. Seminário de metodologia de práticas em saúde da mulher: relatório. Olinda: SOS-CORPO; 1988.

17. Corrêa S. Gênero: reflexões conceituais, pedagógicas e estratégicas - relações desiguais de gênero e pobreza. Olinda: SOS-CORPO; 1994.

18. Barsted LL. Conquistas da sexualidade no campo do direito. Sexual Gen Soc. 2005; 1(23-25):9-15.

19. Duarte LFD. Ethos privado e justificação religiosa: negociações da reprodução na sociedade brasileira. In: Heilborn ML, Duarte LFD, Peixoto C, Barros ML, organizadores. Sexualidade, família e ethos religioso. Rio de Janeiro: Garamond; 2005. p. 137-76.

20. Bonan C. Reflexividade, sexualidade e reprodução: encruzilhadas das modernidades latino-americanas. Iberoamericana. 2005; 5(18):89-107.

21. Ministério da Saúde. Aborto e saúde pública no Brasil: 20 anos. Brasília (DF): MS; 2009.

22. Miguel LF, Biroli F. Apresentação. Rev Bras Cienc Polit. 2012; (7):19-23.

23. Heilborn ML, Cabral CS, Brandão E, Faro L, Cordeiro F, Azize R. Itinerários abortivos em contexto de clandestinidade na cidade do Rio de Janeiro - Brasil. Cienc Saude Colet. 2012; 17(7):1699-708. 
PROFISSIONAIS DE SAÚDE E O ABORTO: ...

Lemos A, Russo JA. Los profesionales de salud y el aborto: lo dicho y lo no dicho en una capacitación profesional en salud. Interface (Botucatu). 2014; 18(49):301-12.

El objetivo del estudio fue analizar la visión de los profesionales sobre el aborto y su relación con la práctica profesional. Las profesionales aquí analizadas participaron del curso del Programa de Atención Íntegra a la Salud de la Mujer/Contracepción. Estudio descriptivo con abordaje cualitativo y etnográfico. Hubo observación participativa, uso de cuestionario y entrevistas con 11 profesionales de salud. En el curso se abordó la cuestión del aborto de una forma problematizada y dialogada, como un problema de salud pública. En general, el discurso predominante durante el módulo teórico del curso fue el posicionamiento contrario a la práctica del aborto utilizando argumentos de naturaleza religiosa. No obstante, esa posición fue relativizada en el momento de las entrevistas. Aunque de forma parcial, el curso proporcionó al grupo un proceso de reflexión sobre su práctica profesional, un factor importante para las personas envueltas en la capacitación de profesionales de la salud.

Palabras-clave: Aborto inducido. Derechos sexuales y reproductivos. Capacitación profesional. Personal de salud.

Recebido em 04/08/13. Aprovado em 13/03/14

312 (C) Interface comunicação saúde Educação 2014; 18(49):301-I2 